\title{
LAS PREPOSICIONES EK Y ПPO $\Sigma$ EN EL NUEVO TESTAMENTO. DOS CASOS ESPECIALES: ROM 1,4 Y MC 10,5
}

\author{
Marta Merino Hernández \\ Universidad de Córdoba \\ martmerino1@hotmail.com \\ https://orcid.org/0000-0003-4459-5889
}

\begin{abstract}
RESUMEN
El uso bíblico de las preposiciones દ̇א y $\pi \rho o ́ \varsigma$ proporciona ejemplos en los que el significado de una preposición está abierto a diferentes interpretaciones, lo que hace necesaria la adopción de un enfoque metodológico principalmente semántico (sin prescindir del aspecto morfosintáctico). Asimismo, el examen de las preposiciones por parte de los principales diccionarios dedicados al griego clásico y neotestamentario, resulta insuficiente desde el punto de vista semántico. Nuestro trabajo parte, en cambio, de la aplicación de la metodología de análisis semántico seguida para la redacción del Diccionario Griego-Español del Nuevo Testamento (DGENT) al examen de غ̇א en Rom 1,4, un pasaje donde el valor temporal y causal del morfolexema se confunde con el de origen o el instrumental. Igualmente se llevará a cabo un análisis del significado de $\pi \rho o ́ \varsigma$ en Mc 10,5, donde se produce confusión entre el valor de correspondencia del morfolexema, el causal y el de relación.
\end{abstract}

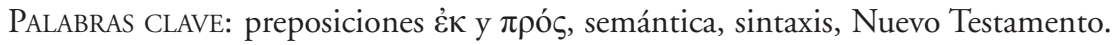

\author{
THE PREPOSITIONS EK AND ПPO $\Sigma$ IN THE NEW TESTAMENT GREEK. \\ TWO SPECIAL CASES: ROM 1,4 AND MK 10,5
}

\section{ABSTRACT}

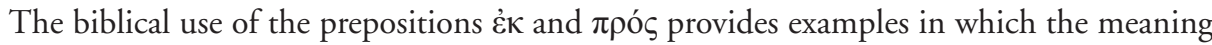
of a preposition is open to different interpretations, which makes necessary the adoption of a methodological approach mainly semantic (without excluding the morphosyntactic aspect). Furthermore, the analysis of the prepositions carried out by the main dictionaries devoted to classical Greek and New Testament Greek, is insufficient from the semantic point of view. However, our work begins with the application of the methodology of semantic analysis followed by the drafting of the Greek-Spanish Dictionary of the New Testament (DGENT) and the analysis of $\dot{\varepsilon} \kappa$ in Rom 1,4, a passage where the temporal and causal values of the morpholexeme are confused with origin or instrumental values. Likewise, an analysis of the meaning of $\pi \rho$ ó $\varsigma$ will be carried out in Mk 10,5, where there is confusion between the causal value, the correspondence value and the relationship value of the morpholexeme.

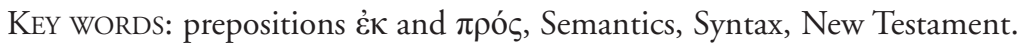




\section{INTRODUCCIÓN}

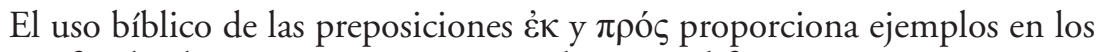
que el significado de una preposición está abierto a diferentes interpretaciones. Ello provoca que este tipo de morfolexemas llegue a convertirse, en ocasiones, en el centro de un debate interpretativo (Campbell, 2017: 39 y 41), especialmente, en griego bíblico.

Así nos centraremos en el estudio de dos pasajes que presentan controversia

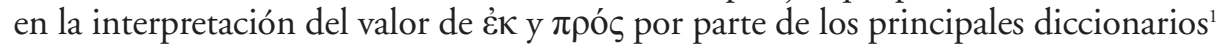
de griego clásico y neotestamentario, así como en algunas traducciones, gramáticas y estudios. De este modo, examinaremos el uso de غ̇K en Rom 1,4, un pasaje concerniente a la resurrección y constitución de Jesús «con plena fuerza / poder» como mediador de la salvación humana y la consecuente liberación de los pecados, donde el valor temporal y causal del morfolexema se confunde con algunas otras funciones como la de origen o la instrumental. Igualmente se llevará a cabo un análisis del significado de $\pi \rho o ́ \varsigma$ en Mc 10,5, dedicado a Jesús y el acta de repudio, donde se produce confusión entre el valor de correspondencia del morfolexema, el causal y el de relación, siendo necesario un análisis semántico de los valores de estos morfolexemas en dichos versículos, así como la adopción de un enfoque metodológico principalmente semántico (sin prescindir del aspecto morfosintáctico), así como estructural. Para ello aplicaremos la metodología del $D G E N T^{2}$, lo que nos permi-

\footnotetext{
${ }^{1}$ Asimismo, de acuerdo con la metodología del DGENT, el primer paso para el estudio del

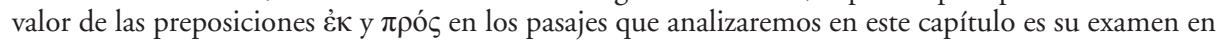
los principales diccionarios de griego clásico y neotestamentario. Ello ha corroborado que el análisis de ambos morfolexemas por parte de estos diccionarios resulta, igual que en el caso de otras preposiciones, insuficiente desde el punto de vista semántico. Remitimos a la entrada correspondiente a $\dot{\varepsilon} \kappa$

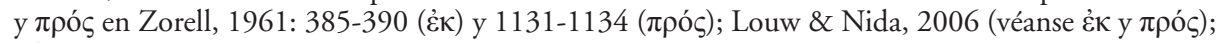

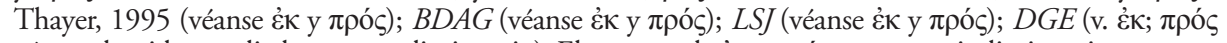

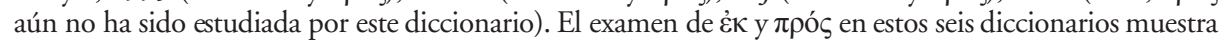
un claro desacuerdo entre los diferentes léxicos acerca de significados de ambas preposiciones.

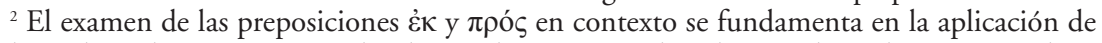
la metodología de análisis semántico utilizada por el DGENT en la redacción de sus lemas, que se basa en cinco principios básicos:

a) Diferenciación sistemática entre significado y traducción en la redacción de los lemas;

b) establecimiento de la fórmula semántica (que, por motivos de espacio, omitimos en este artículo), cuya finalidad es identificar qué especies semánticas constituyen el morfolexema (desarrollo sémico), no solo las denotadas sino también las connotadas;

c) redacción, a partir de la citada fórmula semántica, de la definición del significado lexical de los lexemas, que consiste en una descripción del mismo, acompañada por la traducción correspondiente. Este mismo procedimiento se aplicará a cada uno de los diferentes sememas o acepciones del lexema;

d) indicación del factor o factores contextuales que determinan del cambio de significado de los lexemas de manera individualizada y

e) examen de todos los contextos en los que se encuentra el lexema dentro del corpus neotestamentario.
} 
tirá dilucidar cuál es la esfera significativa de ambos morfolexemas ${ }^{3}$ en contexto $\mathrm{y}$, en consecuencia, la adecuada interpretación exegética en cada pasaje.

La primera parte de este artículo analizará las características propias de la preposición غ̇א, desde dos perspectivas, lexico-semánticas y gramaticales, centrándonos en su articulación del tiempo, la causa, el instrumento y el origen. Atenderemos, además, a los rasgos y factores que, según la semántica funcional y cognitiva, permiten diferenciar dichas nociones entre $\mathrm{si}^{4}$.

La segunda constituirá el primer núcleo de este estudio, es decir, el análisis

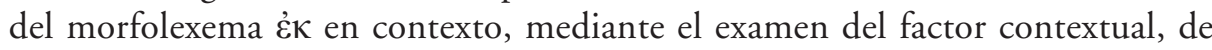
acuerdo con la metodología del DGENT, así como a través de dichos rasgos semánticos, lo que permitirá deslindar qué noción denota el morfolexema en este caso. Así, trataremos de dilucidar su significado en Rom 1,4.

La tercera y cuarta parte estarán dedicadas al estudio de los rasgos propios del morfolexema $\pi \rho o ́ \varsigma$, especialmente, en lo que se refiere al valor de correspondencia y relación de esta preposición. Del mismo modo, centrándonos en elucidar el factor contextual que determina ambas nociones, trataremos de resolver los desacuerdos entre diccionarios, traducciones, gramáticas y estudios acerca del valor del morfolexema en Mc 10,5. Por último se expondrán las conclusiones de este estudio, que abre nuevas vías para el estudio de la sintaxis y la semántica preposicional.

${ }^{3}$ Es importante recordar que las variadas extensiones de significado desarrolladas por el influjo de la sintaxis y el contexto en el que se encuentra una preposición surgen a partir del significado lexical que esta posee y que provee de una línea de continuidad entre ellas (Porter, 1992: 142; Harris, 2012: 27). Recordemos que, según Bortone, 2010: 85, dicha línea de continuidad constituye una red de extensiones metafóricas surgidas a partir del citado significado lexical. En efecto, para delimitar la noción expresada por una preposición es necesario comenzar por la idea encerrada en la raíz, la cual debe matizarse con la función propia del caso del sustantivo con el que compone el sintagma preposicional y el contexto inmediato (Alexandre, 2016: 196).

El contexto, por tanto, se revela como un elemento imprescindible para dilucidar el significado de esta clase de morfolexemas, difíciles en su estudio, tanto sintáctico como semántico, debido, no solo a que estamos ante una categoría gramatical muy compleja, ambigua y polisémica, expuesta, a menudo, a sutiles matices de significado, sino también, a que su sistema en griego complementa al de los casos, lo que lo convierte en un terreno de estudio a medio camino entre lo gramatical y lo lexical.

Recordemos que, en este estudio, se entiende por significado lexical aquel a partir del cual surge el resto de acepciones de un lexema dado en una entrada del diccionario, el cual constituye la primera acepción. Louw y Nida, sin embargo, consideran significado lexical el «Conjunto de rasgos semánticos (componentes semánticos o semas) de un término". El significado contextual es "aquel que resulta de adiciones efectuadas al núcleo sémico y / o de alteraciones producidas en el núcleo sémico mismo o en la figura nuclear de un lexema por los clasemas y semas ocasionales, y que exige una nueva definición. Equivale a acepción» (Peláez, 1996: 63).

${ }^{4}$ El trabajo de Bendor-Samuel 1996 es un buen ejemplo de que el análisis de los roles semánticos es de gran ayuda para la interpretación de los textos a nivel exegético. 


\section{LA PREPOSICIÓN EK. OBSERVACIONES PRELIMINARES}

El morfolexema preposicional غ̇א, que, originalmente, proviene de la forma $\grave{\varepsilon} \xi$, y aparece así delante de vocal (Humbert, 1960: 307-308), ocupa el tercer lugar en cuanto a frecuencia (915), respecto al resto de las preposiciones propias en el NT. Etimológicamente, se deriva, por asimilación, de la forma $\varepsilon \gamma, \varepsilon \chi(D E L G: 353$ ss.), rige un único caso, el genitivo (ablativo), (Alexandre, 2016: 207-208) y su uso, aunque menos variado, es más común que el de ảjó, con el que, a menudo, se solapa en la expresión del genitivo ablativo en griego helenístico y neotestamentario ${ }^{5}$, debido a su creciente proximidad semántica ${ }^{6}$. Ambas preposiciones desarrollaron, además, significados abstractos semejantes como la codificación del genitivo partitivo ${ }^{7}$, debido a que sus valores concretos están muy próximos (Alexandre, 2016: 203; Bortone, 2010: 147-148 y 150). Por lo demás, غ̇א, que es la forma más común para denotar origen en griego (Luraghi, 2003: 129-130), suele aplicarse con mayor frecuencia a

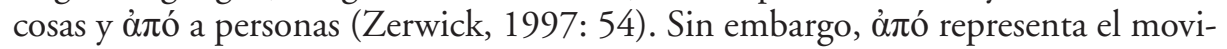
miento desde el borde o superficie de un objeto, mientras que $\dot{\varepsilon} \kappa$, como veremos, lo hace desde el interior de este (Harris, 2012: 103; Porter, 1992: 154; Alexandre, 2016: 203; Bortone, 2010: 164). Por lo demás, ḋंó y غ̇א no son completamente sinónimas, ya que, a menudo, غ̇א marca un punto de referencia concreto ${ }^{8}$, mientras que ả $\pi$ ó indica simplemente el punto de referencia general del que el movimiento o la acción procede (Harris, 2012: 57) ${ }^{9}$. Dicha distinción entre ambos morfolexemas

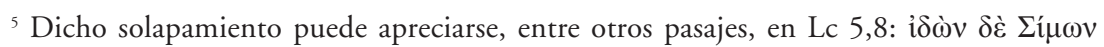

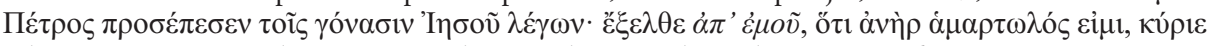
«al ver esto, Simón Pedro se postró a los pies de Jesús, diciendo: Apártate de mí, Señor, que soy un

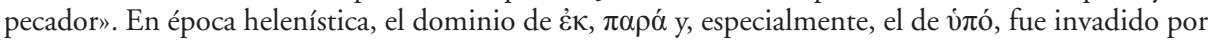

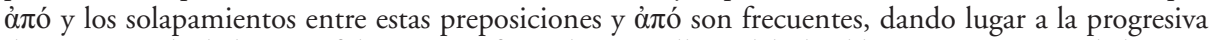
desaparición de dichos morfolexemas en favor de ảió. Ello es debido al histórico aumento de la sinonimia en el sistema preposicional griego. Además, este fenómeno se produce tanto en los sentidos espaciales como en los no espaciales de dichos morfolexemas (Bortone, 2010: 67, 147-148, 150, 165 y 185; Luraghi, 1996a: 106; Crespo, 2003: 240; Blass \& Debrunner, 1961: 114-115; Moule, 1953: 72; Moulton, 1963: 259 y 302-303; Wallace, 1996: 368; Harris, 2012: 57-58).

${ }^{6}$ Incluso desde Heródoto en adelante (Luraghi, 2003).

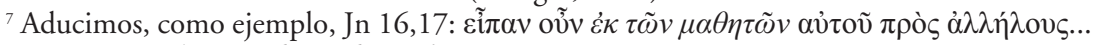
"comentaron entonces algunos de sus discípulos entre sí...».

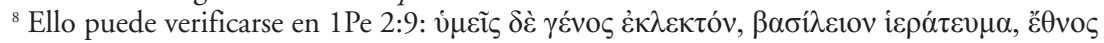

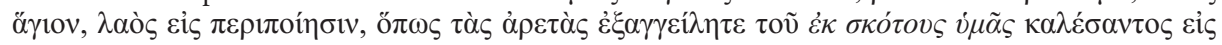

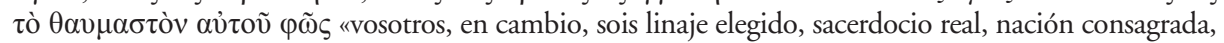
pueblo adquirido por Dios, para publicar las proezas (Is 43,20-21) del que os llamó de las tinieblas a su maravillosa luz».

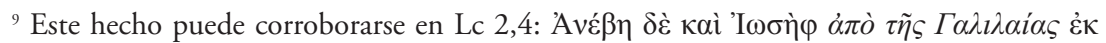

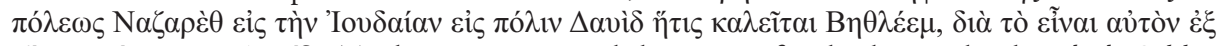
ớkov Kaì $\pi \alpha \tau \rho \imath \tilde{\alpha} \varsigma \Delta \alpha v i ́ \delta$, «También José, por ser de la estirpe y familia de David, subió desde Galilea, de la ciudad de Nazaret, a Judea, a la ciudad de David, que se llama Belén». 
sigue siendo aplicable, aunque tal vez de modo menos sistemático, en el griego helenístico y neotestamentario (Bortone, 2010: 155).

De acuerdo con su significado lexical, દ̇א denota procedencia y separación, indicando punto de partida en el espacio o en el tiempo y expresando el movimiento desde el interior (Dutton, 1916: 49) hacia fuera de un lugar u objeto con el que había estado en íntima conexión, por lo que ėK expresa, de algún modo, la ruptura de alguna conexión (Harris, 2012: 103; Luraghi, 2003: 95-106; Moule, 1953: 72; Alexandre, 2016: 203 y 207-208; Robertson, 2006: 597; Jannaris, 1897: 380; Crespo, 2003: 171; Porter, 1992: 154; Bortone, 2010: 164). De esta noción original, de carácter espacial, se desarrolló, debido a que las preposiciones son elementos léxicos usados con mucha frecuencia y el uso erosiona el significado lexical, una noción no espacial metafórica de fuente, así como sus respectivos usos figurativos de origen, agentividad (por), base (en base a), causa (por) y medio $(\text { por medio de })^{10}$.

La definición del significado lexical de ė́ que proponemos es: «Marca de origen o separación desde el interior o las inmediaciones de un lugar o término». Se traduce por de, de dentro de, desde el interior de, desde, fuera de (denotando procedencia); de, a partir de (indicando separación).

A continuación, examinaremos no solo el valor temporal, causal, de origen e instrumental de $\dot{\varepsilon} \kappa$, sino también el factor contextual que determina la existencia de dichos significados de acuerdo con la metodología del DGENT. Ello nos permitirá dilucidar qué noción puede aplicarse con certeza a ėk en Rom 1,4 donde, como se ha mencionado antes, dichos valores son confundidos entre sí por los investigadores.

\section{LA EXPRESIÓN DE TIEMPO MEDIANTE EK + GENITIVO}

El examen de esta preposición en algunos textos del $\mathrm{NT}^{11}$ revela un segundo significado de $\dot{\varepsilon} \kappa$, pues, por extensión de la noción local de fuente o significado lexical de la preposición (Bendor-Samuel, 1996: 105), el morfolexema غ̇K adquiere valor temporal en el NT cuando acompaña a términos o expresiones que indican

${ }^{10}$ Los distintos valores de esta preposición pueden consultarse, a falta aún de un estudio completo de દ̇א por parte del DGENT, en Harris, 2012: 103-104; Alexandre, 2016: 207-208; Delgado

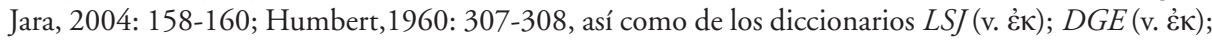

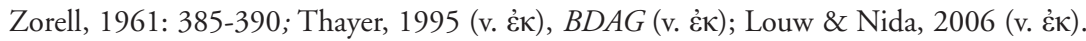

${ }^{11}$ A falta de un estudio completo por parte del DGENT, se han tomado como referencia de los valores de la preposición غ̇א estudiados en este capítulo, los versículos neotestamentarios citados por los siguientes diccionarios, los cuales han sido analizados: LSJ (v. غ̇א); Zorell, 1961: 385-390;

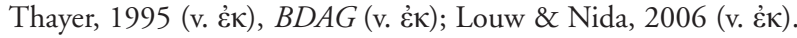


tiempo, cantidad, así como eventos que constituyen hitos ${ }^{12}$, denotando el momento inicial de un lapso de tiempo de manera más intensa que àmó (Dutton, 1916: 49).

Su definición es: "Punto de partida temporal de algo»; se puede traducir por de, desde.

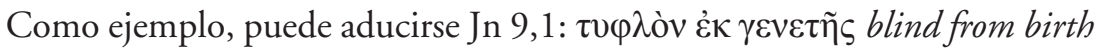
«ciego de nacimiento».

Del mismo modo, en ocasiones, غ̇к puede denotar sucesión, cuando aparece con numerales ordinales y en construcciones paronomásticas. Su definición es:

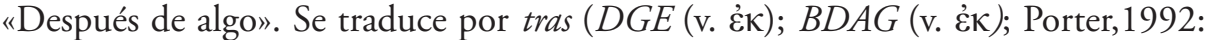

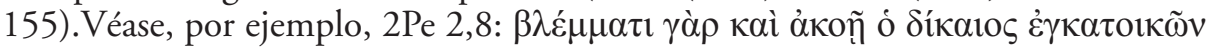

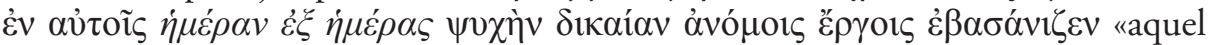
justo, con lo que veía y oía mientras convivía con ellos, día tras día sentía despedazarse su espíritu recto por sus obras inicuas».

\section{LA EXPRESIÓN DE ORIGEN (METAFÓRICO) MEDIANTE EK + GENITIVO EN EL NT}

La expresión de origen constituye una extensión metafórica de la noción local de fuente o significado lexical de ék surgida mediante la denominada metáfora de fuente, indicando el punto en el espacio desde el que se origina la acción verbal, lo que convierte la noción de movimiento concreto en solo una idea abstracta de propagación. Además, esta aparece, generalmente, cuando el morfolexema acompaña a verbos o expresiones de movimiento, transferencia, posesión y eje-

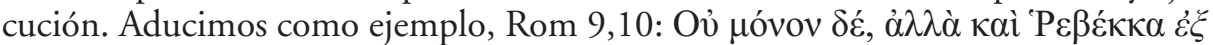

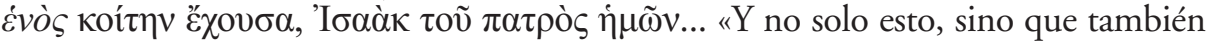
cuando Rebeca concibió de un hombre, de Isaac nuestro padre...».

Por último es reseñable que la noción de origen suele mediar entre la de fuente espacial y otras nociones como la causa, el instrumento, etcétera (Luraghi, 2003: $21-22$ y 37$)$.

Puede definirse así: «Marca de procedencia de algo o alguien». Se traduce por de, desde, de parte de.

\section{LA EXPRESIÓN DE LA CAUSA MEDIANTE EK (EN LUGAR DE YחO) + GENITIVO EN EL NT}

La gramaticalización del uso de la preposición ė $\kappa$ para expresar la causa eficiente en lugar de vंđó queda atestiguada en griego bíblico y helenístico (Moulton,

${ }^{12}$ La influencia de las características semánticas del término regido por una preposición sobre la sintaxis preposicional ha sido reconocido, con frecuencia, por los estudios lingüísticos de los últimos veinte años. Dichos rasgos corresponden en la realidad a atributos propios de ciertos referentes, a tenor de los cuales un determinado rasgo semántico establece la aparición de un lexema en un sintagma determinado, de acuerdo con nuestras creencias sobre el mundo y la estructura de los eventos. 
1963: 259; Luraghi, 2003: 98) de manera más frecuente que en el caso de àđó (Dutton, 1916: 49). Ello es debido a que se trata de una expresión de la fuente de movimiento; este tipo de codificadores a menudo vienen a indicar naturalmente causas o agentes. En consecuencia, al igual que vं $\pi$ ó, غ̇א se refiere a la fuente última de causalidad (Luraghi, 2003: 98). Así, el morfolexema pasó, mediante la metáfora de fuente, de la noción lexical de origen a la de causa, pues ambos significados denotan la noción de «surgir de» (Harris, 2012: 103) ${ }^{13}$.

Los puntos de referencia con $\dot{\varepsilon} \kappa$ en las expresiones causales son, prototípicamente, sustantivos abstractos, especialmente, verbales de acción o estado (o pronombres cuyos antecedentes son sustantivos de esta clase) (Luraghi, 2003: 98). Además, la causa puede atribuirse a una extensa multiplicidad de realidades, debido a que no existe una clase natural de causas; estas van desde fuerzas naturales, emociones, conceptos abstractos y seres animados hasta sucesos. Asimismo el valor causal puede aparecer en una extensa diversidad de acciones ${ }^{14}$. Todo ello hace difícil la explicitación de las características léxicas propias de los términos con los que la preposición puede codificar este valor (Luraghi, 1994: 236; Luraghi, 1996b: 140; Martínez Vázquez, 2000: 646-647).

Su definición es: «Por motivo de». Se traduce como por, por causa de, debido a.

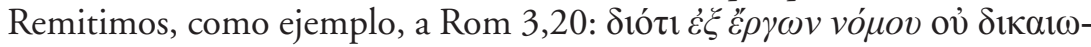

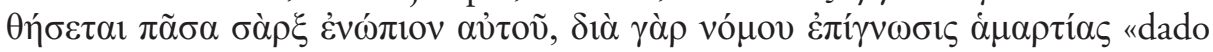
que "ningún mortal quedará rehabilitado ante él" por haber observado la Ley. De hecho, la función de la ley es dar conciencia del pecado».

Los rasgos característicos de la causa son, únicamente, cierto grado de intencionalidad y control (Martínez Vázquez, 2000: 640-641), según la semántica funcional, y ha sido definida, prototípicamente, por esta corriente lingüística como una «entidad, situación o persona que provoca o posibilita un estado de cosas sin tener control (en ocasiones completo control) sobre él». Del mismo modo, cuando la función causal se atribuye a seres humanos, estos suelen provocar la realización de la acción sin intención ni control sobre esta (Luraghi, 1994: 236; Luraghi, 1996b: 117, 122 y 144). Por último, se diferencia del agente de predicación pasiva en que la causa no concurre con otra entidad que soporte un cambio de estado (un paciente).

${ }^{13}$ Otros autores, como Luraghi, aducen, aunque de manera poco convincente, creemos, que el significado causal se deriva metafóricamente de la noción temporal de la preposición. Esto explicaría por qué los puntos de referencia con غ̇k en las expresiones de causa son sustantivos abstractos (Luraghi, 2003: 98).

${ }^{14}$ Además, la función de causa puede articularse en griego tanto mediante un dativo como mediante un sintagma preposicional formado por las siguientes preposiciones: $\alpha$ đó más genitivo, $\delta$ ió

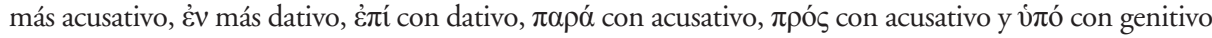
(Alexandre, 2016: 295). 


\section{LA EXPRESIÓN DE INSTRUMENTO O MEDIO CON EK + GENITIVO EN EL NT}

La función de instrumento o medio constituye uno de los valores metafó-

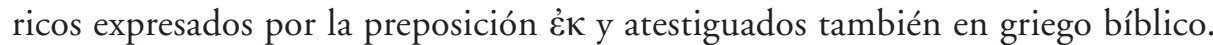
Denota el medio o instrumento mediante el cual un agente realiza la acción verbal. Dicho significado se desarrolló, igualmente, a partir del valor local del morfolexema, mediante la denominada metáfora de fuente, ya que el instrumento es visto como el punto en el espacio desde el que se origina la acción verbal (Luraghi, 2000: 278).

Su definición es: «Por medio de». Se traduce como: por, mediante, a través de, con.

Asimismo, los instrumentos o medios suelen estar representados por una realidad material o abstracta (o pronombre cuyo referente es un sustantivo de esta naturaleza) que es utilizado por un agente, al menos implícito, exclusivamente, en acciones controladas. A esto hay que añadir, como señala la semántica cognitiva, que, prototípicamente, los instrumentos son entidades inanimadas y manipulables (la manipulación es su principal característica y suelen aparecen con predicados de acción manipulativa) ${ }^{15}$. Además, se refieren típicamente a instrumentos naturales, es decir, herramientas, armas, medios de transporte y similares.

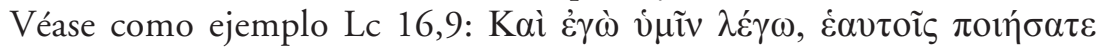

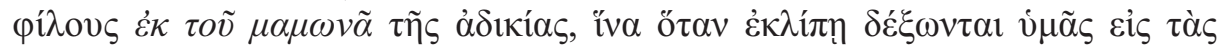

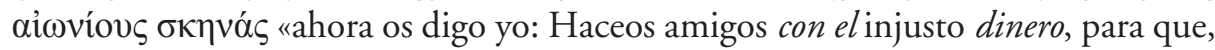
cuando se acabe, os reciban en las moradas definitivas».

Los medios, que pueden considerarse dentro de la función instrumental ${ }^{16} \mathrm{y}$ no como un rol aparte, son representados por entidades, generalmente, abstractas, utilizadas por un agente con el fin de lograr cierto estado de cosas, pero manipuladas en menor medida que un instrumento (Luraghi, 2003: 33-36). Esta función

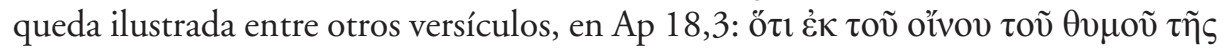

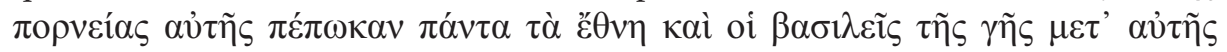

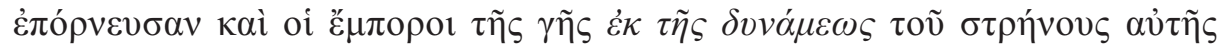

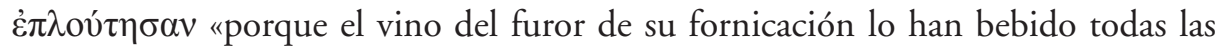
naciones, los reyes de la tierra fornicaron con ella y los comerciantes se hicieron ricos con su lujo desaforado».

${ }^{15}$ Otros verbos con los que غ̇א suele articular la función instrumental son verbos de crianza, búsqueda, compra o consunción, servicio o ayuda, demostración, etc.

${ }^{16}$ Según, Luraghi, debido a que no parece haber una forma específica de codificación en griego para el rol semántico de medio, no debe configurarse este rol como algo separado del instrumento (Luraghi, 2013b). 
La causalidad se encuentra semánticamente próxima, no solo a la noción de origen ${ }^{17}$, sino también a la de instrumento o medio. Esto se debe a que todos ellos representan puntos de referencia que dan comienzo a una acción o participan en su realización, ya que comparten la citada metáfora de fuente (Luraghi, 2003: 33-36; Porter, 1992: 155). Esto crea dificultades de interpretación textual, como veremos más adelante en Rom 1,4.

Desde el punto de vista de la semántica cognitiva, -que considera las funciones semánticas como nociones graduales que tienen ciertos puntos de estrecha proximidad y otros de extrema diferenciación- la causalidad y la instrumentalidad son definidas como categorías radiales estructuradas alrededor de un prototipo caracterizado por una serie de propiedades. En el caso de la causa, estas son la ausencia total o parcial de los rasgos de control e intencionalidad sobre la acción verbal involucrada y, en el de la instrumentalidad, el hecho de participar en acciones controladas, así como en concurrencia con un agente. Por tanto, la noción de control de la acción representa el elemento diferenciador entre la causa y el instrumento (Luraghi, 1994: 230; Luraghi, 1996b: 140-141; Martínez Vázquez, 2000: 644-646 y 640-641) ${ }^{18}$.

\section{ROM 1,4: UN CASO DE CONTROVERSIA RESPECTO AL VALOR DE LA PREPOSICIÓN EK EN EL NT}

Rom 1,4 es un versículo teológicamente importante, pero que constituye un caso de discusión, tanto entre los diccionarios y estudios específicos como entre las diversas traducciones respecto al significado y la traducción de la preposición غ̇к.

${ }^{17}$ La noción de origen por parte del morfolexema que nos ocupa puede apreciarse en Hch

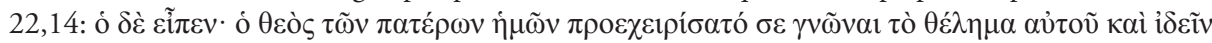

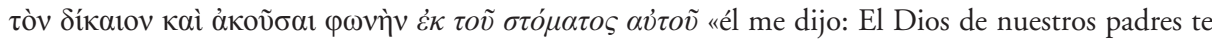
destinó a que conocieras su designio, vieras al Justo y escucharas palabras de su boca».

${ }^{18}$ Como ejemplo del uso de Ėא en función causal puede aducirse Rom 3,20, donde el rasgo

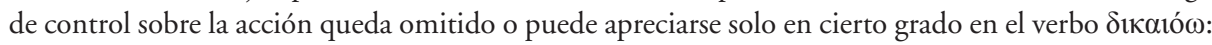

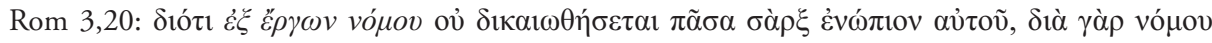

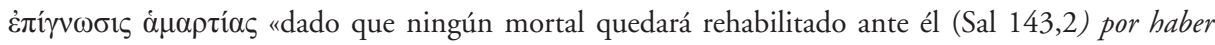
observado la Ley. De hecho, la función de la ley es dar conciencia del pecado».

La función instrumental del morfolexema puede observarse en Lc 16,9. En este pasaje, el verbo que acompaña a la preposición es $\pi$ oté $\omega$, el cual posee claramente el rasgo de control. Véase Lc 16,9:

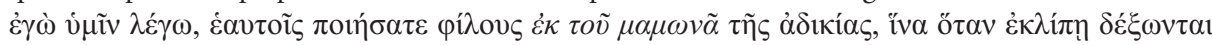

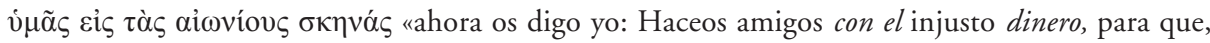
cuando se acabe, os reciban en las moradas definitivas». 


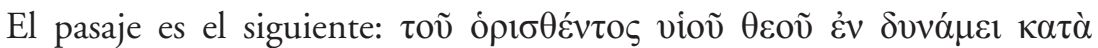

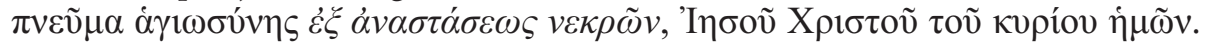

Del significado y traducción de la preposición ék en este texto depende la interpretación del pasaje que gira en torno a la constitución de Jesús como hijo de Dios «con plena fuerza / poder». Dicho debate se centra sobre el modo como esto tuvo lugar. ¿Cómo sucedió, por tanto, "por medio de» su resurrección de la muerte, «por causa de» su resurrección de la muerte o, por el contrario, «a partir de» ella? Así, por una parte, tanto el léxico de Zorell (1961: 385-390) como el Thayer

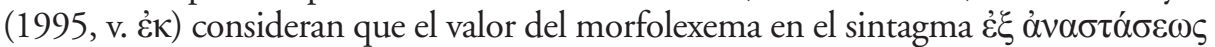

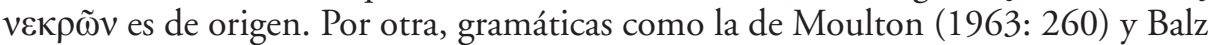
\& Schneider (2005: 1226) aducen que es difícil deslindar si el valor de la adposición en Rom 1,4 es causal o temporal. Lo mismo establecen Douglas Moo (1996: 73) y Moule (1953: 48) en sus respectivos estudios. Porter, sin embargo, lo considera temporal, indicando tiempo desde el que algo ocurre (Porter, 1992: 155). Por último, estudios específicos como el de Harris (2012: 111) aducen que el uso del morfolexema puede considerarse tanto temporal como instrumental.

La misma divergencia de opiniones puede observarse en distintas traducciones, elegidas al azar, como la de Reina Valera [RVA (2015)], la New Revised Standar Version [NRSV (1989)] y la New King James Version [NKJV (1982)], las cuales parecen atribuir a la adposición en este versículo el valor de marcador de causa o instrumentalidad:

RVA (2015): y quien fue declarado Hijo de Dios con poder según el Espíritu de santidad por su resurrección de entre los muertos-, Jesucristo nuestro Señor.

$N R S V$ (1989): and was declared to be Son of God with power according to the spirit of holiness by resurrection from the dead, Jesus Christ our Lord.

NKJV (1982): And declared to be the Son of God with power, according to the spirit of holiness, by the resurrection from the dead.

Dichas versiones contrastan, sin embargo, con las castellanas de Nácar Colunga [NC (1999)] y Cantera Iglesias [CI (2015)] de cuya lectura se deduce que

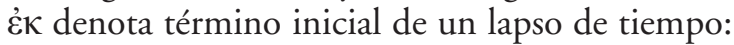

NC (1999): constituido Hijo de Dios en poder según el Espíritu de santidad a partir de la resurrección de entre los muertos, Jesucristo nuestro Señor.

CI (2015): que fue constituido Hijo de Dios con poder, según [el] Espíritu de santidad, desde [su] resurrección de [entre los] muertos, Jesucristo Juestro Señor.

\section{ANÁLISIS DEL VALOR DE EK EN ROM 1,4. LA RESURRECCIÓN Y LA CONSTITUCIÓN DE JESÚS COMO HIJO DE DIOS CON PLENA FUERZA / PODER}

$\mathrm{Al}$ partir de las observaciones precedentes, la delimitación de la noción expresada por $\dot{\varepsilon} \kappa$ en este pasaje puede ser resuelta, principalmente, atendiendo al contexto. En primer lugar, contra el supuesto valor figurativo de origen, aducido por los diccionarios Zorell y Thayer, puede afirmarse que dicho uso aparece, generalmente, con 
verbos de movimiento y transferencia, posesión, así como de ejecución (BendorSamuel, 1996: 103-104), lo que no corresponde con el sentido del verbo ópí̧ $\omega$ (fijar,

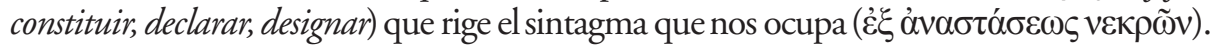

En segundo lugar, no resulta del todo convincente la afirmación de la gramática de Moulton ni la de Douglas Moo, ni la de Moule (Moulton, 1963: 260; Moo, 1996: 73; Moule,1953: 73) de la existencia de un posible valor causal de la preposición en este pasaje, pues, de acuerdo con la semántica funcional y cognitiva, los rasgos característicos de la causa son, la ausencia o solo cierto grado de intencionalidad y control ${ }^{19}$, lo que no parece cumplirse en el caso del sintagma $\tau$ toṽ

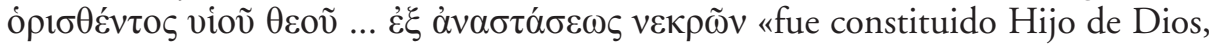
... por su resurrección de la muerte», pues ópí́ç se refiere a una acción decididamente controlada e intencional.

Del mismo modo, resulta dudosa la hipótesis de un posible valor instrumental de la preposición en Rom 1,4 denotando la idea de que Jesús adquirió pleno poder divino "a través de la resurrección", a pesar de que se cumplen todas las características propias del rol instrumental en este contexto, lo que ha dado lugar a la confusión, por parte de estudiosos como Harris (2012: 111), del valor instrumental con el temporal en este pasaje. Así, غ̇א articula dicho valor en una acción controlada como la expresada por el verbo ópí̧ fijar, definir, declarar, rige término

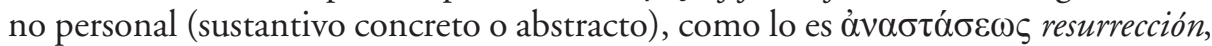
y se da un tercer rasgo propio del valor instrumental: la concurrencia con un agente, aunque en este caso está implícita: Dios. No obstante, la aparición, tan próxima al

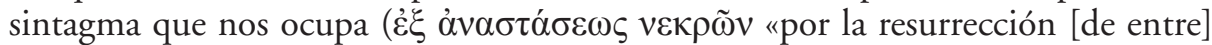

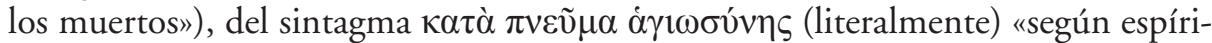
tu de santidad» (Zerwick, 2008: 539) indicando concordancia, conformidad o correspondencia y afirmando que es conforme al Espíritu de Santidad / santo que habita en él ${ }^{20}$ como Cristo fue declarado hijo de Dios, provoca una lectura ambigua (Harris, 2012: 248), pues no estaría claro si Jesús adquiere pleno poder divino mediante la resurrección (instrumentalidad) o según el Espíritu de santidad / santo

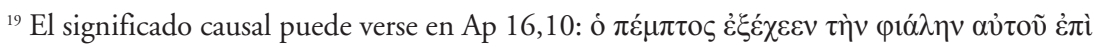

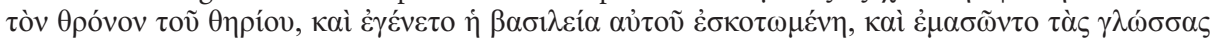

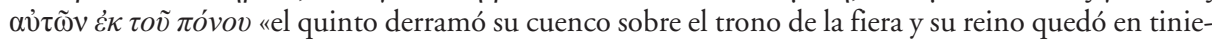
blas; los hombres se mordían la lengua a causa del dolon».

${ }^{20}$ Hendriksen, 1990: 32-34, considera que se trata del Espíritu Santo. No obstante, otros autores entienden $\kappa \alpha \tau \alpha \grave{\alpha} \pi v \varepsilon \tilde{v} \mu \alpha \dot{\alpha} \gamma 1 \omega \sigma u ́ v \eta \varsigma$ «según espíritu de santidad», como «según su naturaleza eterna como hijo de Dios» (Jamieson, Fausset \& Brown, 2002: 337) y no como «Espíritu Santo». Ello puede deducirse no debido a la ausencia del artículo en este sintagma, como opinan algunos

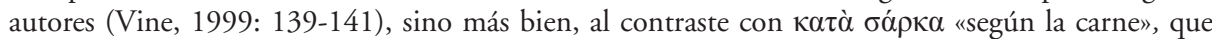
compara la naturaleza humana proveniente de la filiación davídica de Jesús, en el versículo anterior, Rom 1,3 (Vine: 1999: 1432), con su filiación divina en Rom 1,4. A la misma conclusión llega Mahan, 1987, pp. 10-12. 
(concordancia). Ambos significados son considerablemente similares, ya que el medio con el que algo se hace puede considerarse también un modo de hacerlo.

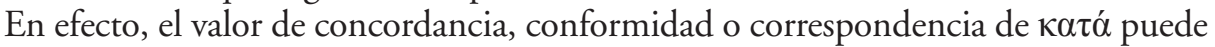
considerarse un valor modal del morfolexema ${ }^{21}$.

En cambio, la asunción de un posible valor temporal, indicando el «punto inicial de un lapso de tiempo" (de, desde) propuesta por Porter, Moulton, Moo, Moule y Harris (Porter, 1992: 155; Moulton, 1963: 260; Moo, 1996: 73; Moule, 1953: 73; Harris, 2012: 248), puede atestiguarse en este pasaje. No obstante, la dificultad de elucidación de dicho valor en Rom 1,4 se debe a una elipsis del obligado término temporal que debe regir la preposición y que se refiere al «momento» de la resurrección. Es necesario recordar que el valor temporal de $\dot{\varepsilon} \kappa$ aparece cuando el morfolexema acompaña a términos o expresiones que indican lapso de tiempo, cantidad o aparece en construcciones paronomásticas indicando sucesión (DGE, v. غ̇א);

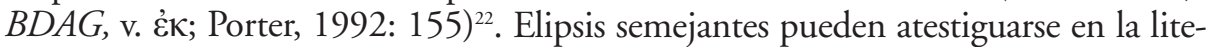
ratura clásica. Así ocurre en el siguiente pasaje de Píndaro $\chi \omega ́ \rho \alpha$... $\tau \alpha \mu \imath \varepsilon v o \mu \varepsilon ́ v \alpha$ ¿̇ $\xi$ Aíxkov «región administrada desde (los tiempos de) Éaco» (Olympia 8.30) (Snell \& Maehler, 1987), donde la adposición no rige explícitamente un término temporal, pero sí lo hace implícitamente.

Por ello, nuestra traducción (Mateos \& Schökel, 1987) de Rom 1,4: $\tau$ võ

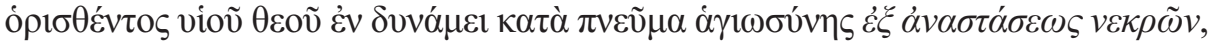

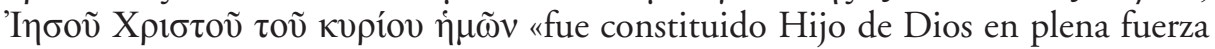
según Espíritu de santidad / Espíritu Santo (Mateos \& Schökel, 1987: 279), a partir de su resurrección de la muerte» parece transmitir más nítidamente la idea de que la filiación divina «en pleno poder» otorgada a Jesús queda inaugurada «en el momento» de su resurrección y no "por causa de» o "por medio de» esta, lo que queda verificado también por estudios como el W. Hill (2015: 157).

De este modo, la investidura de Jesús en pleno poder no se hace depender de la resurrección, ni como efecto, en el caso de un posible valor causal, ni como

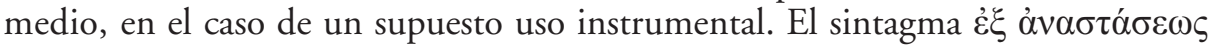

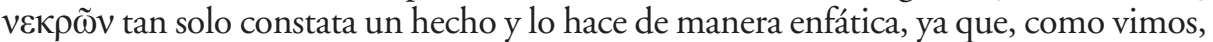

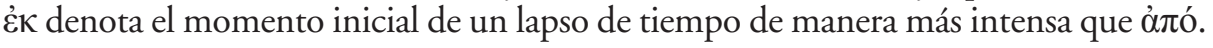

\section{LA PREPOSICIÓN ПPOऽ. OBSERVACIONES PRELIMINARES}

El uso del morfolexema preposicional $\pi \rho{ } \varsigma$ en el griego bíblico ocupa el quinto puesto en cuanto a frecuencia (700) (Porter, 1992: 172) respecto al de las otras preposiciones "propias" y rige tres casos: genitivo (ablativo) de punto

${ }^{21}$ Véase un ejemplo del valor adverbial de modo (como, conforme, en armonía con) del

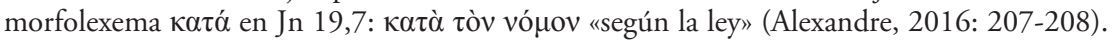

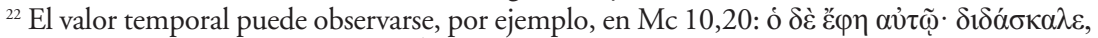

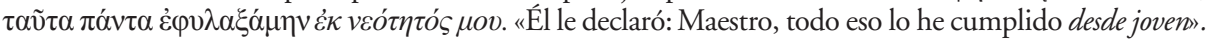


de partida, dativo (locativo) de posición espacial y acusativo de dirección (Humbert, 1960: 317). Su etimología no está clara, aunque parece derivarse de $\pi \rho 0 \tau i ́$, encontrada en Homero (Robertson, 2006: 622-623). En comparación con el griego clásico, su uso neotestamentario está marcado por un notable aumento de su uso con acusativo debido al incremento de la utilización de este caso en griego helenístico en lugar del dativo, lo que ocasionó el progresivo y temprano debilitamiento de este

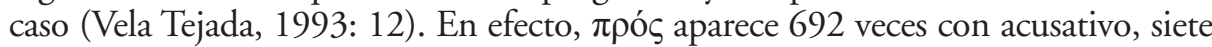
con dativo: Mc 5,11; Lc 19,37; Jn 18,16; 20,11, 12ab; Ap 1,13 (todas ellas en sentido espacial) y llega casi a su desaparición con genitivo (solo una vez en Hch 27,34).

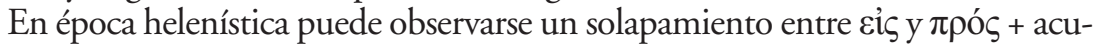

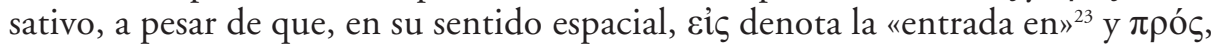

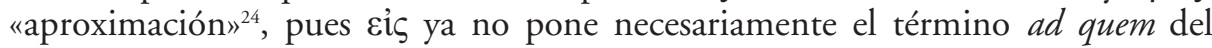
movimiento en la cosa misma, sino (a menudo) en su proximidad (Zerwick, 1997: 56 y 172-173), acercándose al sentido de $\pi \rho{ }^{25} \varsigma^{25}$. Asimismo, zỉ suele acompañar a términos no personales y $\pi \rho o ́ s$, en cambio, a término personal (Harris, 2012: 81-82 y 190). Este solapamiento es paralelo, en cierta medida, al que se da entre àđó y غ̇̌. Además, $\pi \rho o ́ \varsigma$ es antónima de àmó (de, desde) (Porter 1992: 172).

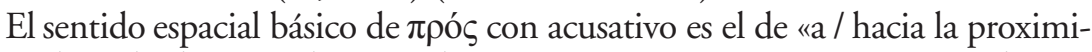
dad de», indicando dirección hacia un lugar, así como posición u orientación de cara a algo ${ }^{26}$, es decir, denota la meta o límite hacia el cual se dirige un movimiento, así como la aproximación hacia (la concretización de) un objetivo psicológico. De este último sentido de dirección mental del morfolexema surge la noción de relación amigable u hostil. Sucesivamente, esta idea de orientación psicológica conduce al uso de $\pi$ pó $\varsigma$ para expresar nociones como la de propósito (con vistas a) (a menudo con infinitivo articular), referencia (en relación con), etcétera (Harris, 2012: 189-190) ${ }^{27}$.

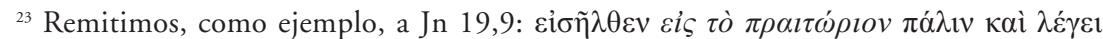

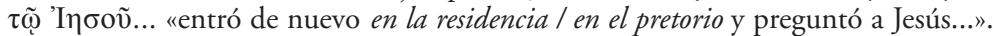

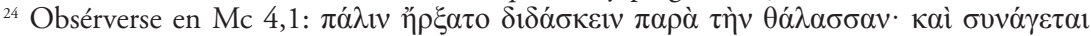

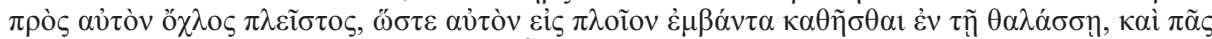

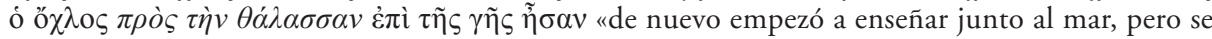
congregó alrededor de él una multitud grandísima; él entonces se subió a una barca y se quedó sentado, dentro del mar. Toda la multitud se quedó en la tierra, de cara al mans.

${ }^{25}$ Además, en griego clásico, el significado de $\pi \rho o ́ \varsigma$ con genitivo era, en parte, similar al de $\pi \alpha \rho \alpha ́$ + genitivo, con la que, en ocasiones también se solapa, ya que implica una posición o dirección desde el exterior de un punto de referencia. Sin embargo, ambos morfolexemas se diferencian en que $\pi \rho o ́ \varsigma$ implica, a menudo, contacto, mientras que $\pi \alpha \rho \alpha ́$ se limita a indicar posición o dirección desde el área donde se encuentra el punto de referencia (Luraghi, 2003: 286-287).

${ }^{26}$ No obstante, existe desacuerdo acerca de la idea encerrada en la raíz de la preposición, ya que, para algunos es «cerca» y para otros es «hacia» (Robertson, 2006: 623).

${ }^{27}$ Igual que en el caso de $\dot{\varepsilon} \kappa$, puede tomarse como referencia, la clasificación de los valores de $\pi \rho o ́ \varsigma$ realizado por Alexandre, 2016: 221-224; Delgado Jara, 2004: 186; Humbert, 1960: 318; Jannaris, 1987: 395-356; Moulton, 1963: 273-274); Blass \& Debrunner, 1961: 239-241; así como

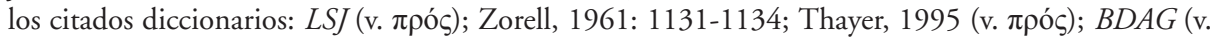
$\pi \rho o ́ \varsigma$ ); Louw \& Nida, 2006 (v. $\pi \rho o ́ \varsigma)$. 
Otros sentidos figurados que se producen con frecuencia en el NT son los de causa, asociación o compañía, ventaja o perjuicio, modo, etcétera (Porter, 1992: 172; DLGE: 940-941).

Se define como «Marca de dirección hacia las inmediaciones de un lugar o término ubicado en el lado opuesto». Su traducción es a, hacia, en dirección a; cerca de, de cara a, enfrente de, junto a.

Seguidamente, analizaremos el valor de correspondencia y el de relación de $\pi \rho o ́ \varsigma$, , estableciendo el factor contextual que provoca dichos significados, según la metodología del $D G E N T$, lo que hará posible determinar qué noción debe aplicarse exactamente al morfolexema en Mc 10,5, donde no hay acuerdo entre los diccionarios, traducciones y estudios consultados sobre cuál de los dos sentidos de la preposición aparece en este pasaje.

\section{LA EXPRESIÓN DE CONCORDANCIA, CONFORMIDAD O CORRESPONDENCIA MEDIANTE ПPO + ACUSATIVO}

El griego del NT también ofrece, siguiendo el uso clásico (Delgado Jara, 2004: 185; Blass \& Debrunner, 1961: 239-241; Harris, 2012: 153), ejemplos del uso de $\pi \rho$ ó $\varsigma$ como marca de correspondencia, indicando el criterio o norma a la luz de la cual se afirma, se hace o se juzga algo. Dicho valor surgió, al igual que el de resultado, a partir del valor direccional con acusativo del morfolexema, ya que, cuando aparece con un punto de referencia abstracto, la noción de dirección local propia de la preposicón se interpreta metafóricamente como orientacion psicológica. Así, dicho punto de referencia puede articular con el morfolexema, entre otros, el valor de concordancia, conformidad o correspondencia de la acción.

Tras un análisis de los pasajes en los que, según los diccionarios $\operatorname{citados}^{28}$, el morfolexema aparece con este valor en el NT puede concluirse que el factor que delimita dicha noción es el hecho de que el morfolexema vaya acompañado bien por un sustantivo abstracto (de acción o estado; en ocasiones, un pronombre), bien de persona (a veces, también, un pronombre) o bien, por un participio sustantivado y verbos de comunicación y transferencia, conocimiento, ejecución, movimiento, suceso, aflicción y muerte.

Se define como «Marca de conformidad o proporción entre dos cosas». Su traducción es: de acuerdo con, con arreglo a, según.

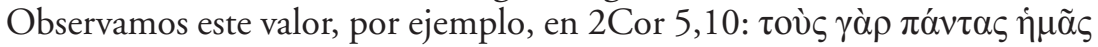

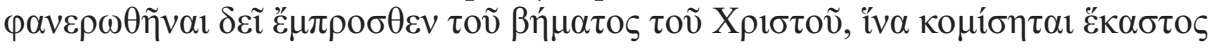

${ }^{28}$ Los valores de la preposicón $\pi \rho o ́ \varsigma$ estudiados en este capítulo han tomado como referen-

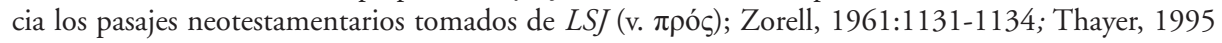

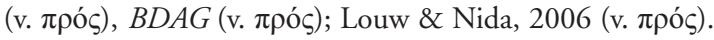




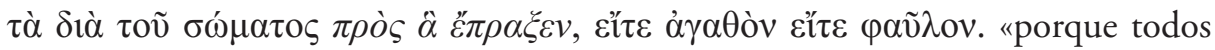
tenemos que aparecer como somos ante el tribunal del Mesías, y cada uno recibirá lo suyo, bueno o malo, según se haya portado mientras tenía este cuerpo».

\section{LA EXPRESIÓN DE RELACIÓN MEDIANTE חPOE + ACUSATIVO}

Es necesario señalar que la noción de relación también es articulada por $\pi \rho o ́ \varsigma$ + acusativo en el griego neotestamentario. Esta noción se deriva, metafóricamente, al igual que la anterior, del significado direccional de $\pi \rho{ }^{\prime} \varsigma$, pasando a articular la referencia a un área abstracta hacia la que apunta la acción verbal (Luraghi, 2003: 295), mediante un desplazamiento metafórico que convierte el espacio concreto en el ámbito de una acción.

De acuerdo con nuestro examen de los versículos en los que el morfolexema denota relación ${ }^{29}$, puede afirmarse que este adquiere dicho valor cuando aparece

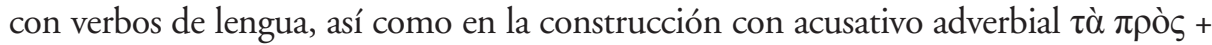
acusativo y, por último, en construcciones elípticas acompañando a un pronombre personal.

Su definición es «Marca de relación o alusión a algo». Se traduce por: con referencia $a$, con respecto $a$, en lo que respecta $a$, en cuanto $a$, en lo que concierne $a$.

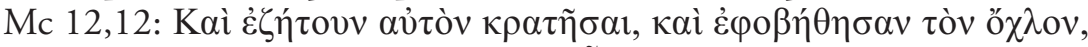

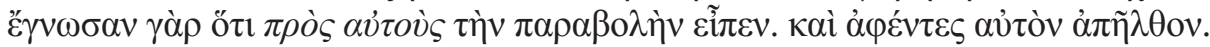
«Estaban deseando echarle mano, porque se dieron cuenta de que la parábola iba por ellos; pero tuvieron miedo de la multitud y, dejándolo, se marcharon».

\section{MC 10,5: UN CASO DE CONTROVERSIA RESPECTO AL VALOR DE LA PREPOSICIÓN ПPO乏 EN EL NT}

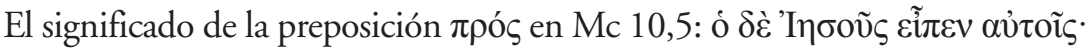

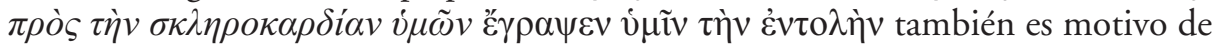
diversa interpretación entre los diccionarios, traducciones, gramáticas y estudios. Así, el ambiguo valor del morfolexema en este pasaje centra la discusión sobre el modo como se produjo el progresivo relajamiento de la estricta moral matrimonial a lo largo de la historia de Israel, llegando a ser tolerado el repudio por las antiguas leyes judías (Coenen, Beyreuther \& Bietenhard, 1990: 49-50). De este modo, el uso de $\pi \rho o ́ \varsigma$

${ }^{29}$ Remitimos a los diccionarios citados en la nota 95 para la consulta de los pasajes en los que dichos léxicos han detectado este valor. Además, hemos consultado este uso en Blass \& Debrunner, 2005: 239-241; Robertson, 2006: 622-626. 
en Mc 10,5 es considerado causal por Zerwick (1997: 57). Por su parte, los diccionarios de Nida, Thayer y $B D A G$ señalan que se trata un valor de relación o referencia del morfolexema, aunque $B D A G$ precisa que, en este pasaje, dicho valor podría ser equivalente a la noción de causa. La ambigüedad del versículo es puesta de manifiesto, por último, por la gramática de Moulton y Blass \& Debrunner (Moulton, 1963: 274; Blass \& Debrunner, 2005: 239-241), quienes puntualizan que indica correspondencia o conformidad con algo, siguiendo el uso clásico, y que se trata de un valor que podría considerarse también equivalente al causal.

No obstante, no parece haber consenso entre los diccionarios, gramáticas y estudios específicos acerca de la existencia de un valor causal de la preposición en

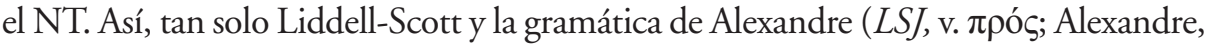
2016: 221-224) hacen referencia a este valor dentro de los sentidos metafóricos del morfolexema. Lo mismo puede decirse de Zerwick, quien aduce este significado en algunos versículos como Mc 10,5 (Zerwick, 1997: 57). Otros no lo citan, como $B D A G$, Thayer, Nida, Moulton o Robertson (Moulton, 1963: 274; Robertson, 2006: 622-626), o consideran que no denota propiamente causa sino estimación (en vista de), como Luraghi y Harris (Luraghi, 2003: 296; Harris, 2012: 189).

En cuanto a las diferentes versiones consultadas, todas parecen apuntar a un sentido causal de la preposición, como puede verse en:

NRSV (1989): But Jesus said to them, «Because of your hardness of heart he wrote this commandment for you».

NKJV (1982): And Jesus answered and said to them, «Because of the hardness of your heart he wrote you this precept».

RVA (2015): Pero Jesús les dijo: -Ante la dureza de corazón de ustedes les escribió este mandamiento.

NC (1999): Díjoles Jesús: «Por la dureza de vuestro corazón os dio Moisés esta ley».

CI (2015): Pero Jesús les dijo: «Os escribió esa norma por vuestra dureza de corazón».

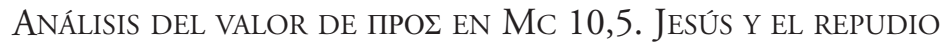

La elucidación del verdadero valor del morfolexema nos lleva a prestar atención al contexto en el que se encuentra la preposición. Así, en primer lugar, nos centraremos en la semántica del verbo con el que esta se articula. En esta ocasión, se trata de $\check{\varepsilon} \gamma \rho \alpha \psi \varepsilon v$ que, en conjunción con el sintagma en el que aparece el morfolexema,

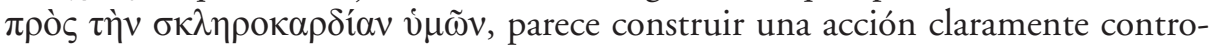
lada e intencional. Así, el discutido valor causal del morfolexema, cuya existencia en el NT solo es defendida por Zerwick, Alexandre y Liddell \& Scott en el LSJ

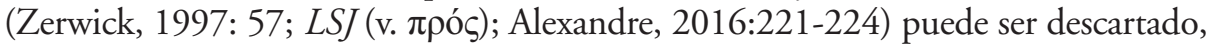
ya que el rol de causa se caracteriza, según la semántica cognitiva y funcional, por aparecer en acciones, generalmente, no controladas y no intencionales o solo con cierto grado de intencionalidad y control. 
Asimismo, según nuestro estudio, tampoco puede aducirse en este pasaje la noción de relación propuesta por Nida, Thayer y $B D A G$, pues esta se da, únicamente, cuando la preposición acompaña a verbos de habla y acusativo de persona o cosa (sustantivo abstracto) o infinitivo sustantivado. El verbo que rige la preposición en este caso es है $\gamma \rho \alpha \psi \varepsilon v$, lo que lleva a concluir que estos tres léxicos han llegado a una conclusión errónea.

Sin embargo, aunque es cierto que este valor parece muy próximo al sentido causal en este pasaje, de acuerdo con nuestro examen ${ }^{30}$, este contexto puede considerarse un ejemplo del uso de $\pi \rho \grave{\varsigma} \varsigma$ como marca de correspondencia o conformidad. Ello coincide, por tanto, con el análisis de la preposición por parte de Moulton y Blass \& Debrunner (Moulton 1963: 274; Blass \& Debrunner, 2005: 239-241), pues este valor surge, generalmente, cuando la preposición aparece, como se dijo más arriba, con sustantivo abstracto o pronombre y, entre otros, con verbos de comunicación (como el verbo que rige la preposición en este caso, es decir, ह̌ $\gamma \rho \alpha \psi \varepsilon v$ ), lo cual parece cumplirse en este pasaje concerniente al repudio ${ }^{31}$.

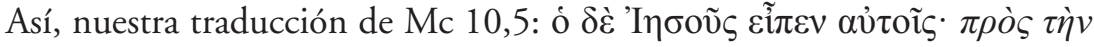

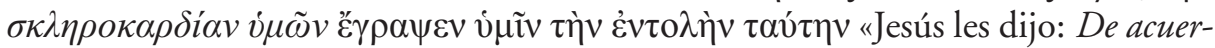
do con vuestra dureza de corazón os dejó escrito Moisés el mandamiento ese», rubrica con mayor precisión el propósito de Marcos en este versículo. El evangelista sintetiza en la respuesta de Jesús a los fariseos la confirmación de que el repudio no fue mera voluntad de Dios, sino una medida, tolerada por necesidad por parte de Moisés, «en función» de la incapacidad de los judíos de aceptar las exigencias de la ley mosaica que hizo que las normas sobre el matrimonio establecidas por Dios bajo la ley

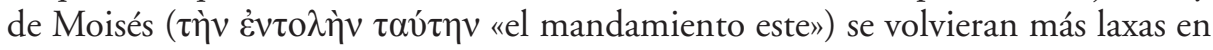
cuanto al repudio (Dt 24,1). Ello queda verificado por el uso de $\pi \rho$ ó $\varsigma$ como marca-

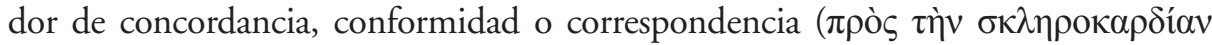
$\dot{v} \mu \tilde{\omega} \nu$ «De acuerdo con vuestra contumacia»).

En este pasaje, por tanto, Jesús burla la pretensión de los fariseos (Mc 10,2-4) de obtener de él una afirmación contraria a la ley de Moisés, según la cual, esta les permitiría repudiar a sus esposas. Ello queda verificado en los siguientes versículos

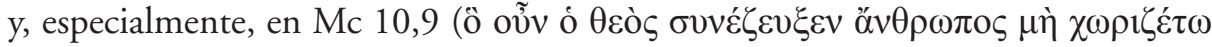
«Luego lo que Dios ha emparejado, que un ser humano no lo separe»).

${ }^{30}$ Como señalaban $B D A G$ (v. $\left.\pi \rho o ́ \varsigma\right)$ y Blass \& Debrunner, 2005: 239-241.

${ }^{31}$ El mismo valor puede apreciarse en el siguiente pasaje paralelo con verbo de transferencia:

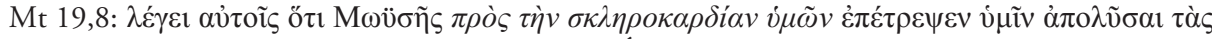

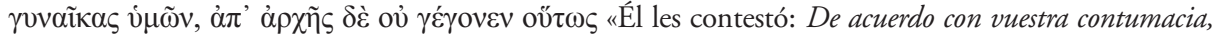
por eso os consintió Moisés repudiar a vuestras mujeres; pero al principio no era así». En este versículo, Mateo subraya el hecho de que en el pasado la ley de Moisés era más estricta en lo referente al matrimonio y no aceptaba el repudio. 
Es necesario recordar que en el NT las normas respecto al divorcio se han vuelto extremadamente estrictas, de un modo sin precedentes en el entorno político, social y religioso de la época. En efecto, el vínculo del matrimonio fue concebido por Dios según la concepción veterotestamentaria, por lo que el matrimonio era una institución indisoluble y cualquier transgresión contra él supone ir contra su voluntad (Mt 19,6ss.) (Jamieson, Fausset \& Brown, 2002: 77). Los hombres y las mujeres debían regirse por las mismas normas, sin concesión alguna a este respecto.

\section{CONCLUSIÓN}

Como se ha puesto de manifiesto en este estudio, el examen de los significados de este tipo de morfolexemas requiere una perspectiva metodológica eminentemente semántico-estructural que no excluya el aspecto morfosintáctico, ya que el contexto es un elemento determinante en la delimitación de la semántica preposicional $^{32}$.

Del mismo modo, de la falta de acuerdo entre algunos de los léxicos examinados sobre el sentido de las preposiciones è y y $\pi$ pó en Rom 1,4 y Mc 10,5, respectivamente, puede deducirse cierta falta de rigor metodológico y de atención al contexto en el que se encuentran ambos morfolexemas. En consecuencia, su análisis parece

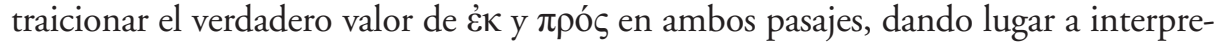
taciones inexactas de su sentido. Así, en el caso de غ̇א, se confunde el valor temporal del morfolexema con el de origen, causa e instrumento. Las diferentes traducciones del NT, las gramáticas y los estudios consultados han mostrado, como se ha visto, cierta imprecisión en su análisis. Por lo demás, también parece poco claro el análisis de $\pi \rho o ́ \varsigma$ en los citados léxicos, traducciones, gramáticas y estudios específicos, ya que confunden el valor de concordancia con el causal y el de relación o referencia.

Igualmente, se ha constatado que las observaciones de la semántica funcionalcognitiva son especialmente de utilidad para delimitar las nociones, semánticamente próximas, de causa e instrumentalidad en el estudio de $\dot{\varepsilon} \kappa$, siendo el rasgo de ausencia total o parcial de control e intencionalidad y la concurrencia con un agente, respectivamente, lo que diferencia ambas funciones entre sí.

Por último, la aplicación de la metodología del DGENT al análisis semántico

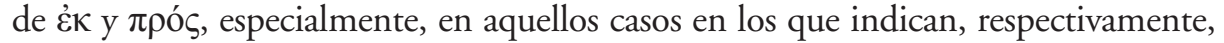
temporalidad y concordancia, constituye, desde nuestro punto de vista, un avance, en el estudio de los valores de ambas preposiciones en el griego del NT. Ya que ha hecho posible dilucidar el ámbito significativo del morfolexema en los versículos

${ }^{32}$ Ello es debido a que el sistema de las preposiciones está a medio camino entre el ámbito de la gramática y el de la lexicografía, pues la noción expresada por una preposición resulta de la combinación del significado de la preposición con el del morfema casual con el que esta se vincula, así como del contenido léxical del núcleo del sintagma, del predicado y de otros factores contextuales. 
elegidos, así como arrojar luz sobre la interpretación de dichos pasajes en los que el valor de la preposición es concluyente para su exégesis. Es de esperar, no obstante, un posterior estudio por parte del DGENT que complete este trabajo analizando

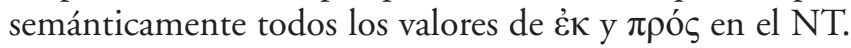

RECIBIDO: octubre 2018; ACEPTADO: diciembre 2018.

\section{REFERENCIAS BIBLIOGRÁFICAS}

Alexandre Júnior, M. A. (2016): Gramática de Griego clásico y helenistico, El Almendro, Córdoba.

BAlz, H. \& Schneider, G. (2005): Diccionario Exegetico del Nuevo Testamento. Vol. I, Ediciones Sígueme, Salamanca.

BDAG = BAUER, W. \& DANKER, F. W. (2006): Bauer-Danker-Arndt-Gingrich Greek Lexicon of the New Testament, en BibleWorks 7. Software for biblical exegesis \& research [CD-ROM], Norfolk, Virginia.

Bendor-Samuel B. A., P. M. (1996): The Exegesis and Translation of Prepositional Phrases in the Greek New Testament. A Semantic Rol Analysis, Oxford Centre for Mission Studies, Oxford.

NKJV (1982): New King James Version, Thomas Nelson, Grands Rapids, Michigan.

NRSV (1989): New Revised Standar Version, National Council of Churches (NCC), New York.

Blass, F. \& Debrunner, A. (1961): A Greek Grammar of the New Testament, University Press, CambridgeChicago.

Bortone, P. (2010): Greek prepositions: From Antiquity to the Present, Oxford University Press, Oxford.

CAmpbell, C. R. (2017): «Prepositons and Exegesis. What's in a word?», en D. L. AkIN \& T. W. Hudgins (eds.), Getting into the Text: New Testament Essays in Honor of David Alan Black, Pickwick Publications, Eugene, Oregon, pp. 39-54.

CI = CANTERA, F. \& IgLESIAS, M. (eds.) (2015³): Sagrada Biblia. Versión crítica sobre los textos hebreo, arameo y griego, Biblioteca de Autores Cristianos, Madrid.

Coenen, L., Beyreuther, E. \& Bietenhard, H. (1990): Diccionario Teológico del Nuevo Testamento. Vol II, Ediciones Sígueme, Salamanca.

Crespo, E. (2003): Sintaxis del griego clásico, Gredos, Madrid.

DGE = Rodríguez Adrados, F. \& al. (2013): Diccionario Griego-Español, Madrid.

DGENT = MATeOs, J. (†), PelÁEZ, J. \& GASCO (2000-): Diccionario Griego-Español del Nuevo Testamento. Análisis semántico de los vocablos, El Almendro, Córdoba.

Delgado Jara, I. (2004): «Estudio de los valores de las preposiciones "propias" en el griego del Nuevo Testamento", Helmantica: Revista de filología clásica y hebrea 55 (167): 149-188.

$D L G E=$ ChanTRAINE, $\mathrm{P}\left(1977^{4}\right):$ Dictionnaire étymologique de la langue grecque: histoire des mots, Klincksieck, Paris.

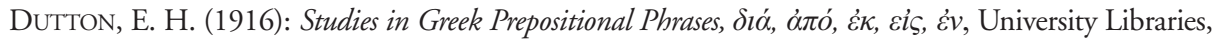
Chicago.

Harris, M. J. (2012): Prepositions and Theology in the Greek New Testament, Zondervan, Michigan. 
Hendriksen, W. (1990): Comentario al Nuevo Testamento, Libros Desafío, Grand Rapids, Michigan. HILl, W. (2015): Paul and the Trinity: Persons, Relations, and the Pauline Letters, Eerdmans, Grand Rapids. Humbert, J. (1960): Syntaxe Grecque, Librairie C. Klincksieck, Paris.

Jamieson, R., Fausset A. R. \& Brown, D. (2002 17 : Comentario Exegético, Casa Bautista de Publicaciones, El Paso.

JANNARIS A. N. (1897): An Historial Greek Grammar, Macmillan, London.

Louw, J. P. \& NidA, E. A. (eds.) (2006): Greek-English Lexicon of the New Testament based on Semantic Domains, en BibleWorks 7. Software for biblical exegesis \& research [CD-ROM], Norfolk, Virginia.

LSJ = Liddell, H. G. \& SCOTT, R. \& al. (1996) Greek-English Lexicon, Clarendon Press, Oxford.

LuRAGHI, S. (1994): «Animate Nouns in Cause Expression», en B. JACQUINOD (ed.), Cas et prépositions en grec ancien. Contraintes syntaxiques et interprétations sémantiques. Actes du colloque international de Saint-Etienne, 3-5 juin 1993, Publications de l'Université, Université de SaintÉtienne, pp. 227-237.

LURAGHI, S. (1996a): «Il rapporto fra caso e preposizione all interno del sintagma preposizionale», en S. LuRAGHI (ed.), Studi su casi e preposizioni nel greco antico, Franco Angeli Edizioni, Milano, pp. 59-110.

LURAGHI, S. (1996b): «Determinazioni di Causa e Strumento nel greco classico», en S. LURAGUI (ed.), Studi su casi e preposizioni nel greco antico, Franco Angeli Edizione, Milano, pp. 111-145.

LuRAGHI, S. (2000): «Spatial Metaphors and Agenthood in Ancient Greek», en M. OfiTsCH \& C. ZINKO (eds.), 125 Jahre Indogermanistik in Graz : Festband anlässlich des 125jährigen Bestehens der Forschungsrichtung "Indogermanistik» an der Karl-Franzens-Universität Graz, Leykam, Graz, pp. 275-290.

Luraghi, S. (2003): On the Meaning of Prepositions and Cases. The expression of semantic roles in Ancient Greek, John Benjamins Publishing Company, Amsterdam-Philadelphia.

LuRAGHI, S. (2006): «Greek Prepositions: Patterns of Polysemization and Semantic Bleaching», en E. Crespo, J. De La Villa \& A. R. Revuelta, Word Classes and Related Topics in Ancient Greek. Proceedings of the Conference on "Greek Syntax and Word Classes», Madrid del 18 al 21 de junio de 2003, Peeters Publishers \& UAM, Paris-Madrid, pp. 487-499.

Mahan, H. T. (1987): Comentario breve a las epístolas, Editorial Peregrino S.A, Alcázar de San Juan, Ciudad Real.

Martínez VÁzquez, R. (2000): «Sobre la distinción entre Agente y Causa en griego antiguo», Habis 32: 639-657.

MateOS, J. \& SCHÖKEL, L. A. (trans.) (1987²): Nuevo testamento, Ediciones Cristiandad, Madrid.

Moo, D. J. (1996): The New International Commentary on the New Testament. The Epistle to the Romans, William B Eerdmans Publishing Co, Grand Rapids.

Moule, C. F. D. (1953): An Idiom book of the New Testament Greek, Cambridge University Press, Cambridge.

Moulton J. H. (ed.) (1963): A Grammar of New Testament Greek. Vol. 3. Syntax, by N. Turner, Edimburgo.

NC = NÁCAR, E. \& Colunga, A. (trans.) (1999): Sagrada Biblia. Versión directa de las lenguas originales, Biblioteca de autores cristianos, Madrid. 
Peláez, J. (1996): Metodología del Diccionario Griego-Español del Nuevo Testamento, El Almendro, Córdoba.

PORTER, S. E. (1992): Idioms of the Greek New Testament, JSOT Press, Sheffield.

ROBERTSON, A. T. (2006): Grammar of the Greek New Testament in the Light of Historical Research, Hodder \& Stoughton, London.

RVA (2015): Reina Valera Actualizada, Editorial Mundo Hispano, El Paso, TX.

Snell, B. \& Maehler, H. (ed.) (1987): Pindari Carmina cum fragmentis I. Bibliotheca scriptorum Graecorum et Romanorum Teubneriana, de Gruyter, Munich-Leipzig.

ThaYer, J. H. \& al. (1995): Greek-English Lexicon of the New Testament, en BibleWorks 7. Software for biblical exegesis \& research, Hendrickson Publishers Inc., Peabody, Massachusetts.

VELA TEJADA, J. (1993): «La reestructuración funcional del sistema preposicional griego en la koiné», Habis 24: 235-247.

VINE, V. E. (1999): Diccionario expositivo de palabras del Antiguo y Nuevo Testamento, Grupo Nelson Nashville.

Wallace, D. B. (1996): Greek Grammar Beyond the Basics: An Exegetical Syntax of the New Testament, Zondervan, Grands Rapids, Michigan.

ZerWICK, M. (1997): El griego del Nuevo Testamento, Verbo Divino, Estella, Navarra.

ZERWICK, M. (2008): Análisis gramatical del griego del Nuevo Testamento, Verbo Divino, Estella, Navarra.

Zorell, F. (1961³), Lexicon Graecum Novi Testamenti, Lethielleux, Paris. 
